\title{
Developing Programmed Learning Material for Teaching Science of CBSE Class IX
}

\author{
Himanshu Tripathi $^{1 *}$, Dr. JE Merlin Sasikala ${ }^{2}$
}

Keywords: Learning Material, Teaching Science, CBSE, Class IX

We will begin by discussing the early history of programmed learning and showing how the interpretation of the term has evolved over the years. The origin of programmed learning had its roots in behavioural psychology- the new 'scientific' school of psychology that was pioneered by the American psychologist B F Skinner during the 1950's. Behavioural psychology was based on what is generally referred to as the stimulus response (S-R) model of behaviour. One important feature of the original stimulus-response model of learning was the concept of successive reinforcement. Another feature is that a desired S-R bond would be firmly established if the learner was supplied with immediate feedback in the form of the correct answer immediately after attempting a particular learning task such as answering a question. Another feature of Skinner's original theory was that each successive stimulus-response step should be small enough to ensure that the learner was nearly always correct in his or her response.

\section{Principles of programmed learning:}

\begin{tabular}{|l|l|}
\hline Principles & Explanation \\
\hline $\begin{array}{l}\text { Active learner } \\
\text { response }\end{array}$ & $\begin{array}{l}\text { To what extent a learner can understand is judged by making him/her answer } \\
\text { questions. The extent of a learner's understanding is ascertained from what is } \\
\text { demonstrated in the responses. }\end{array}$ \\
\hline $\begin{array}{l}\text { Immediate } \\
\text { feedback }\end{array}$ & $\begin{array}{l}\text { Let a learner know whether his/her answer is correct or incorrect immediately. Give } \\
\text { the learner the subsequent question after he/she knows whether his/her response is } \\
\text { right or wrong. }\end{array}$ \\
\hline Small steps & Set small steps in order to prevent a learner from stumbling as much as possible. \\
\hline Self pacing & $\begin{array}{l}\text { Let the learner decide the speed of learning so that he/she can learn at his/her own } \\
\text { pace. }\end{array}$ \\
\hline $\begin{array}{l}\text { Learner } \\
\text { verification }\end{array}$ & $\begin{array}{l}\text { Whether the program is good or bad is judged not based on a specialist's opinion, but } \\
\text { whether learning is actually established or not. To that end, get learners who have yet } \\
\text { to learn the subject matter to try the program under development. Improve the } \\
\text { material as necessary on the basis of trials made. }\end{array}$ \\
\hline
\end{tabular}

\footnotetext{
${ }^{1}$ Research Scholar (Education), Alagappa University, Karaikudi, Tamilnadu, India

${ }^{2}$ Asst. Professor, College of Education, Alagappa University, Karaikudi, Tamilnadu, India

*Responding Author

(C) 2016 I H Tripathi, M Sasikala; licensee IJIP. This is an Open Access Research distributed under the terms of the Creative Commons Attribution License (http://creativecommons.org/licenses/by/2.0), which permits unrestricted use, distribution, and reproduction in any Medium, provided the original work is properly cited.
} 


\section{TYPES (discuss only two basic types):}

Linear programmed learning the first application of Skinner's research to the classroom situation came in the form of the linear programmed learning systems that he developed in 1950 's. In this type of programmed learning, the subject matter was broken down into a sequence of small steps (or frames) that followed logically upon one another. Each of the steps representing only a very small part of the concept or skill being taught. Immediate feedback on the correctness (or otherwise) of the response was designed to provide suitable reinforcement. It was virtually impossible to take a step without having successfully completed preceding ones. There was thus only one possible path which a student could take through the frames - hence the name linear programmed learning. Its structure can be depicted diagrammatically as:

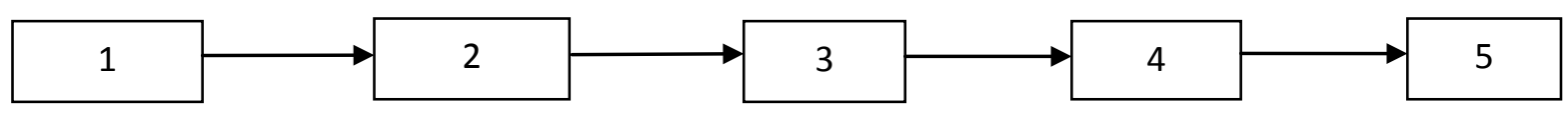

\section{Branching programmed learning}

In early 1960's, a new form of programmed learning known as branching programmed learning was developed. It is based on a result of the work of Norman Crowder. This involved the use of several possible paths through the sequence of frames. These frames are called as remedial frames. The topic to be studied was taught in a number of alternative ways in such a branching programme, depending on the performance of the learner. This would avoid the inflexibility and learner boredom that characterised many early programmes of the linear variety. Such branching programmes now form the basis of much of computer-based learning. The modern interpretation of the term 'programmed learning' is very much broader and more flexible. Neither small steps are considered necessary nor immediate reinforcement. Although most programmes are still described as either 'linear' or 'branching'. Such programmes can now have a much wider range of structures than was ever the case in the past.

\section{(I) Fundamental Principles of Branching Programme:}

(a) Exposition:

Learner should perceive the whole phenomena exposed to him. He would learn better if the whole concept is presented to him.

(b) Diagnosis:

It refers in identifying the weakness of learner. After exposition it is assessed whether student could learn the concept or not. A multiple choice format is used to diagnose the weakness of the learner.

(c) Remediation:

Diagnosis provides the basis for remediation. Remedial instructions are provided on he wrong page. If a learner chooses wrong alternative, he has to move to wrong page where remedial instruction is provided to him to bet back to home page. 
(II) Structure:

(a) Home page/ Content Frame:

It is this page on which the content unit or concept is presented as a frame and followed by multiple choice questions. Its purpose is to impart new knowledge or teaching. MCQ helps in assessing the attainment of the learners. The question aims to diagnose learning difficulties of the students.

Each home page includes the following:

- Repeating student response.

- Positive confirmation.

- New information.

- Question.

- Alternatives followed by frame numbers, where the student should go next.

(b) Wrong Page/ Remedial Frame:

When the learner chooses the wrong response, it indicates the weaknesses or difficulties of learning the concept. He would get further clarification and remediation for the concept so that he may understand the concept. He would be directed to go to the home page where he has to again choose the correct alternative.

\section{Each remedial frame or wrong page includes the following:}

- Repeating student response.

- Negative confirmation.

- Reasons why he is wrong.

- Further explanation in simple language.

\section{(III) Development:}

The following steps are used in the development of a branching programme:

(a) Selection of a topic

(b) Assumptions about learners:

-Entering behavior

-Terminal behavior

(c) Content analysis (preparing flow chart)

(d) Preparing criterion test

(e) Writing programme frames

(f) Try out

(g) Home assignment. Evaluation or validation of the programme.

\section{(IV) Arrangement:}

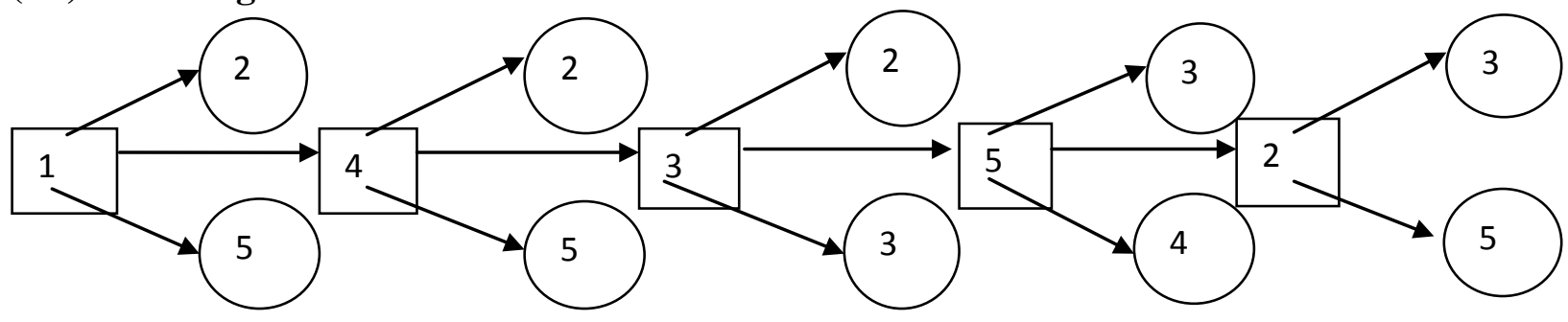




\section{Example:}

In this study we converted the chapter "Laws of Motion" from Science subject of CBSE class IX. The chapter was taught on the principles of Branching Instructions. A part of the chapter converted into framework is shown below:

\section{Frame No. 01:}

Q 1. What is required to change the state of motion of an object?

(a) changes itself (see frame no. 02)

(b) force(see frame no. 04)

(c) climate change(see frame no. 05)

The problem of motion and its causes had puzzled scientist and philosophers. A ball.....its state of motion.

Frame no. 02:

Q 4 (a).Your answer is incorrect. Return to frame No. 04 and read the passage given on the frame carefully.

Q 3 (a).Your answer is incorrect. Return to frame No. 03 and read the passage given on the frame carefully.

Q 1 (a).Your answer is incorrect. Return to frame No. 01 and read the passage given on the frame carefully.

Q 5 (b).Your answer is correct now read the passage given on the frame carefully.

Q2: The person walks on the road because of:

(a) a balanced force(see frame no. 03)

(b) an unbalanced force (see frame no. 05)

(c) an unbalanced force named friction (see after the frame work in exercise)

If children push a box with a small force, the box does not move because of friction....the box starts moving.

\section{Frame no. 03:}

Q 5 (a).Your answer is incorrect. Return to frame No. 05 and read the passage given on the frame carefully.

Q 2 (a).Your answer is incorrect. Return to frame No. 02 and read the passage given on the frame carefully.

Q 4 (c).Your answer is correct now read the passage given on the frame carefully.

Q 3. Which form of force cannot change the state of an object:

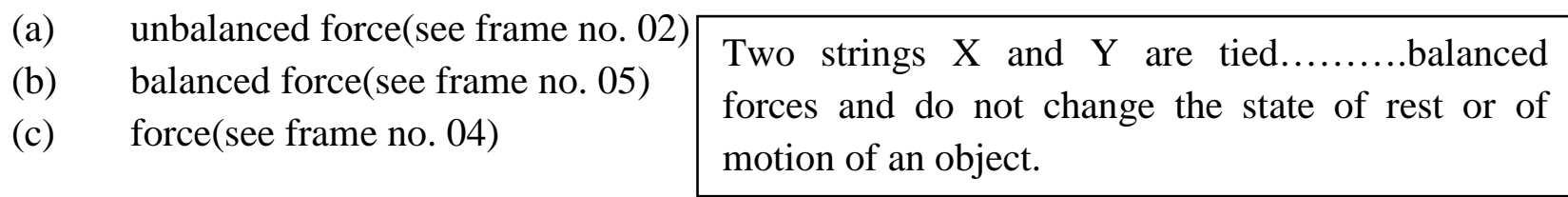


Frame no. 04:

Q3 (c). Your answer is incorrect. Return to frame No. 03 and read the passage given on the frame carefully.

Q1 (b).Your answer is correct now read the passage given below carefully.

Q5 (c). Your answer is incorrect. Return to frame No. 05 and read the passage given on the frame carefully.

Q4. A force can change:

(a) shape of an object (see frame no. 02)

(b) size of an object (see frame no. 05)

(c) shape, size and velocity of an object

Let us now ponder about.........that a force can change the shape and size of objects. (see frame no. 03)

Frame no. 05:

Q4 (b).Your answer is incorrect. Return to frame No. 04 and read the passage given on the frame carefully.

Q1 (c).Your answer is incorrect. Return to frame No. 01 and read the passage given on the frame carefully.

Q3 (b).Your answer is correct now read the passage given on the frame carefully.

Q2 (b).Your answer is incorrect. Return to frame No. 02 and read the passage given in frame carefully.

Q5: Which form of force makes the object to move:

(a) balanced force(see frame no. 03)

(b) unbalanced force (see frame no. 02)

(c) force (see frame no. 04)

Let us consider a situation in which two forces.......that unbalanced force acting on an object brings it in motion

\section{(V) Home Assignment:}

(i) A batsman hits a cricket ball which then rolls on a level ground. After covering a short distance, the ball comes to rest. The ball slows to a stop because:

(a) The batsman did not hit the ball hard enough.

(b) Velocity is proportional to the force exerted on the ball.

(c) There is a force on the ball opposing the motion.

(d) There is no unbalanced force on the ball, so the ball would want to come to rest.

(ii) Friction force can be reduced to a great extent by

(a) Lubricating the two moving parts

(b) Using ball bearing between two moving parts

(c) Introducing a thin cushion of air maintained between two relatively moving surfaces

(d) All the above 
(iii) Force exerted on a body can change its
(a) Kinetic energy
(b) Direction of motion
(c) Speed
(d) Momentum

Answer Q2: an unbalanced force named friction

From the above discussion we came to conclusion with following features and limitations of branching programming:

(VI) Features:

(i) A student learns better if he is exposed with the whole concept.

(ii) Material in a frame is larger. Much information is presented at a time.

(iii) As it is in the form of MCQ- if a learner selects correct response, his response is confirmed and in case he selects wrong response then he is directed to route to the original frame in backward branching or to another in forward branching which explains as to why is he wrong.

(iv) Here wrong response help in diagnosis and providing remediation for their weaknesses.

(v) Highly individualized instruction as it is based on psychology of individual difference.

(vi) Solves problem with high complexity.

(vii) Material so presented is continuously.

(viii) Teaching and remediation go side by side.

(VII) Limitations:

(i) Learner may guess the correct response without understanding the subject matter of the frame.

(ii) Infinite branching cannot be provided. It cannot cater to the needs of the individuals. It is very difficult to find out the total number of branches for each individual.

(iii) Cost of preparation is high.

(iv) Programmer decides the level on content, its frame and diagnostic questions.

(v) Branching model can be used after sixth grade because small children do not follow its mechanism.

(vi) It is very difficult to ask questions on the whole matter of the frames because the frames are two large and sometimes important subject matter is left.

(vii) Guessing.

(viii) Difficulty in arranging the branching sequences.

(ix) Unfeasibility of infinite branching.

(x) No sequence of pages

\section{CONCLUSION}

Programmed instruction may prove a big helping hand in all the tasks and aspects of education. With intelligent application of learning theory strategies and technology, the modern designer will find solutions to the learning requirements of the 21st century. In today's competitive world, 
Programmed instruction may be required to establish and meet the objectives of understanding at cognitive level. On the other hand, the designer may be challenged to provide material that fosters an individual to find divergent approaches to problem solving. Basically originating from the psychology of learning and instruction, it has now been developed as one of the important aspects of instructional technology.

\section{REFERENCES}

Aggrawal, J.C. (2003).Educational technology and management. New Delhi: vinod Pustak Mandir.

Bandura, A. (1997). Social learning theory. Englewood cliffs, NJ: Prentice Hall.

Collins, A., Brown, J.S., \&Holum, A. (1991). Cognitive apprenticeship: Making thinking visible. American Educator, 6-46.

Ely, D.P., T. (1996).Classical writing on instructional technology. Englewood, CO: Libraries unlimited.vol.2.

Gagne, R. (1985).The Conditions of Learning and the Theory of Instruction, (4th Ed.). New York: Holt Rinehart, Winston.

Good, T., Brophy, J. (1990).Educational psychology: A realistic approach. New York: Holt Rinehart, Winston.

Merrill, M.D. (1983).Instructional Design Theories and Models: An Overview of their Current States. Hillsdale, NJ; Lawrence Erlbaum.

Reigeluth, C.M. (1979).In search of a better way to organize instruction: The elaboration theory. Journal of instructional development, 2(3), 8-15.

Shukla , C.(2008). Essentials of educational technology and management New Delhi: Dhanpatrai Publications. 